\title{
Heart Rate Distribution and Aerobic Fitness Changes During Preseason in Elite Soccer Players ${ }^{+}$
}

\author{
Vasilios Kalapotharakos ${ }^{1, *}$, Dimitrios Serenidis ${ }^{2}$ and Savvas Tokmakidis ${ }^{1}$ \\ 1 School of Physical Education and Sport Science, Democritus University of Thrace, 69100 Komotini, Greece \\ 2 School of Medicine, University of Patras, 26221 Patra, Greece \\ * Correspondence: vasikal@yahoo.com \\ + Presented at the 9th Greek Conference of Biochemistry and Physiology of Exercise, Thessaloniki, Greece, \\ 18-20 October 2019.
}

Published: 2 September 2019

\begin{abstract}
Aim: Soccer is characterized as an intense intermittent team sport. Heart rate (HR) is used to monitor the players' training response, as well as to quantify microcycle and mesocycle training intensity during preseason and in-season periods. The purpose of the present study was to quantify the preseason training intensity distribution in elite soccer players and then examine the relationship between HR distribution and changes in aerobic fitness. Material \& Method: Sixteen elite professional soccer players (age, $26.8 \pm 3.8$ years; weight, $77.8 \pm 7.7 \mathrm{~kg}$; height, $1.79 \pm 0.06 \mathrm{~m}$; mean $\pm \mathrm{SD}$ ) participated in the study. Aerobic fitness was evaluated with $\mathrm{VO}_{2}$ max, running velocity at $\mathrm{VO}_{2} \max \left(\mathrm{v}-\mathrm{VO}_{2} \max \right)$ during a laboratory incremental aerobic test and with the distance completed during an interval shuttle run test (ISRT), before and after preseason. HR of each player was measured using a short-range telemetry HR transmitter strap at 5-s intervals during all training sessions of the preseason. The absolute ( $\mathrm{min}$ ) and relative (\%) time spent in high-intensity HR zone (90-100\% of HRmax) during the preseason period was calculated for each player. Results: $\mathrm{VO}_{2} \mathrm{max}$ and distances completed during ISRT improved significantly $(p<0.05)$ by $3.3 \pm 2.1 \%$ and $29 \pm 16 \%$, respectively. The time $(\%)$ players spent in high-intensity training was significantly correlated $(p<0.01)$ with the changes $(\%)$ in distance completed during ISRT. Conclusions: These results provide useful information about the HR quantification during preseason in elite soccer players. Additionally, coaches have to take into consideration the time soccer players spend in high-intensity training for optimal endurance responses when planning and implementing the preseason training period.
\end{abstract}

Keywords: aerobic fitness; heart rate; soccer

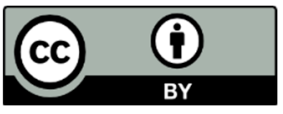

(C) 2019 by the authors. Licensee MDPI, Basel, Switzerland. This article is an open access article distributed under the terms and conditions of the Creative Commons Attribution (CC BY) license (http://creativecommons.org/licenses/by/4.0/). 